\title{
Isolated Female Epispadias with Urinary Incontinence
}

\author{
Shahzad Ali ${ }^{1}$, Hira Moosa ${ }^{2}$ and Saeed Ahmed Khan ${ }^{1}$ \\ ${ }^{1}$ Department of Urology, Jinnah Postgraduate Medical Centre, Karachi, Pakistan \\ ${ }^{2}$ Department of Surgery, Jinnah Postgraduate Medical Centre, Karachi, Pakistan
}

\begin{abstract}
Isolated female epispadias without bladder extrophy is a rare variant of female urethral anomaly reported rarely in the literature. For optimal and early management, early clinical diagnosis is important. Female with isolated epispadias usually presents with primary urinary incontinence with abnormal looking external genitalia on examination. We present a case of a 23-year female with urinary incontinence with bifid clitoris and widely separated labia minora on genital examination. Reconstructive surgery of urethra, labia minora and bifid clitoris was performed in one stage. The goals of management in this case were to achieve urinary continence with reasonable time between voids and cosmetically acceptable female genitalia.
\end{abstract}

Key Words: Epispadias, Bifid clitoris, Urinary incontinence.

How to cite this article: Ali S, Moosa H, Khan SA. Isolated Female Epispadias with Urinary Incontinence. J Coll Physicians Surg Pak 2020; 30(04):438-439. DOI: https://doi.org/10.29271/jcpsp.2020.04.438.

\section{INTRODUCTION}

Female genitourinary system has a complex embryological development. Among the congenital anomalies, urinary anomalies are the third most common isolated female epispadias without bladder extrophy is a rare congenital syndrome with an incidence of one in 484,000 female populations. ${ }^{1}$ The affected female patient usually presents with urinary incontinence with abnormal external genitalia. If careful history and examination are not done properly, this will lead to misdiagnosis. It usually occurs as bladder exstrophy-epispadias complex (BEEC), while isolated epispadias presents as the mildest form. Patients may have flattened mons pubis with absence of pubic hairs, absence of anterior labial commissure, patulous urethra, immature bladder neck, small capacity bladder and incompetent sphincteric mechanism while vagina and internal genital organs are normal. Patients presenting with marked lower urinary tract symptoms along with genital abnormality are commonly diagnosed earlier before adolescence. However in some patients, who are mildly affected, diagnosis may be delayed or missed. ${ }^{2}$ This case is presented here because this problem is very infrequent and although this patient was incontinent since birth; but diagnosis was missed by many clinicians. So, we took proper history and did careful examination of an incontinent female patient, to reach the diagnosis as it is amenable to surgery. The main objective of surgery was to ameliorate the urinary incontinence and to decrease psychosocial and psychosexual problems.

Correspondence to: Dr. Saeed Ahmed Khan, Department of Urology, Jinnah Postgraduate Medical Centre, Karachi, Pakistan

E-mail: narejo.saeed@gmail.com

Received: January 15, 2019; Revised: August 20, 2019

Accepted: August 26, 2019

DOI: https://doi.org/10.29271/jcpsp.2020.04.438

\section{CASE REPORT}

A 23-year female, unmarried, with no known comorbids and normal menstrual cycle presented to us with the complaint of urinary incontinence since birth, with no other urological symptoms. Her developmental milestones were normal. Because of her incontinence, she always remained wet. Her examination was unremarkable except for the external genitalia, which showed widened labia minora, and bifid clitoris. Vagina and hymen were normal (Figure 1). Continuous dribbling of urine was objectively demonstrated. Neurological examination was normal. Baseline investigations were normal.

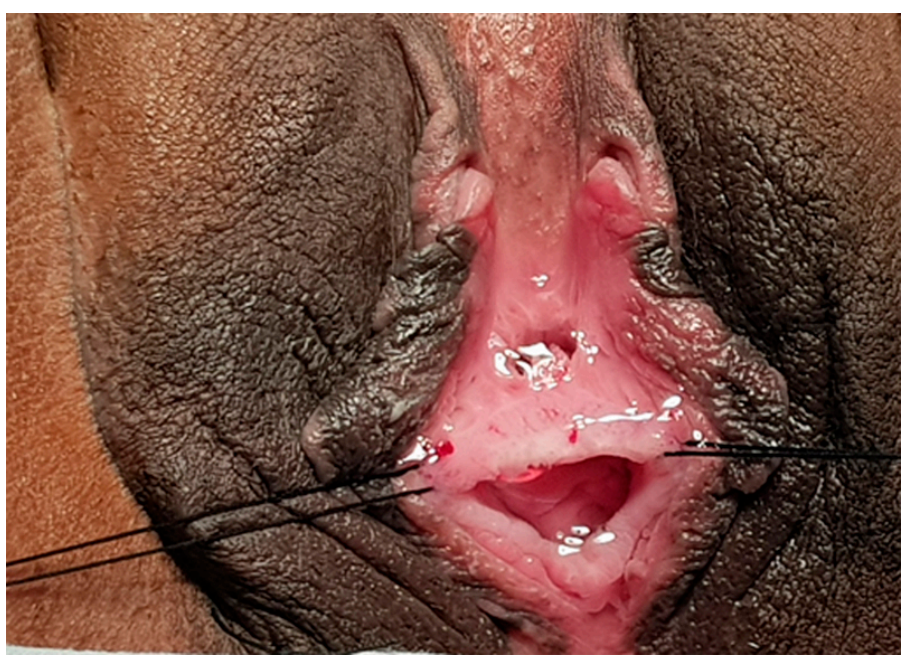

Figure 1: Bifid clitoris, short urethra and normal vaginal opening.

X-ray pelvis was normal. Ultrasound abdomen and pelvis and intravenous pyelography (IVP) were unremarkable.

Cystourethroscopy revealed short urethra, about $0.5 \mathrm{~cm}$, intact and visible bladder neck, and intact both ureteric orifices at normal position, and capacity of bladder of around $100 \mathrm{ml}$.

After establishing the diagnosis of isolated epispadias, she was planned for surgery. After passing 6-F 16-F Foley's catheter, Ushaped incision was made around urethral plate. Urethral plate was 
mobilised and primarily repaired over Foley's catheter using absorbable sutures and clitoroplasty was done (Figure 2). Fat was retrieved from labia majora and repair area was covered with second layer (Figure 3). The procedure was completed with best possible cosmetic reconstruction of the external genitalia. Foley's catheter was removed at $10^{\text {th }}$ postoperative day. The female was continent postoperatively and remained dry for about 2 hours and voided good volume of urine with good stream.

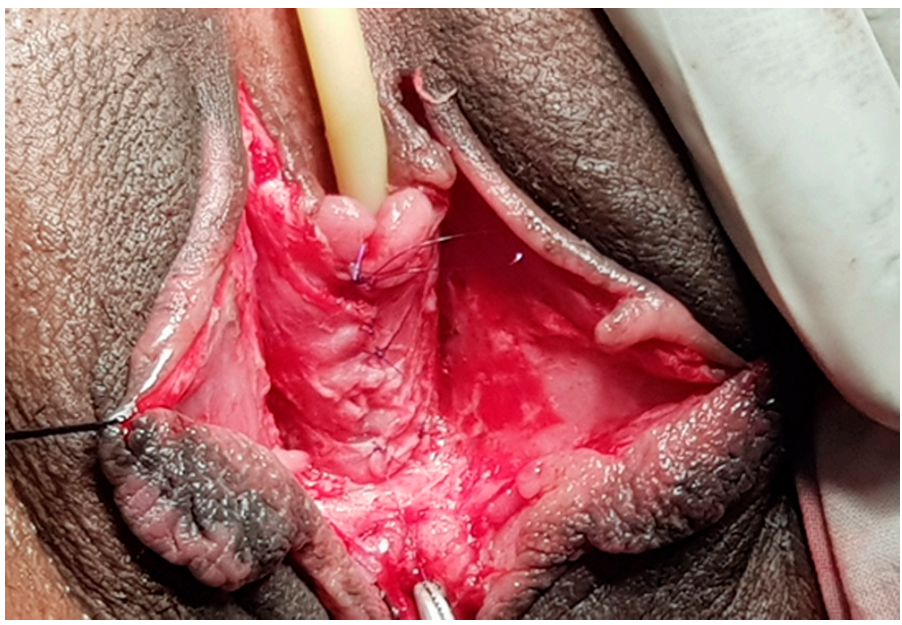

Figure 2: Urethroplasty and clitoroplasty completed.

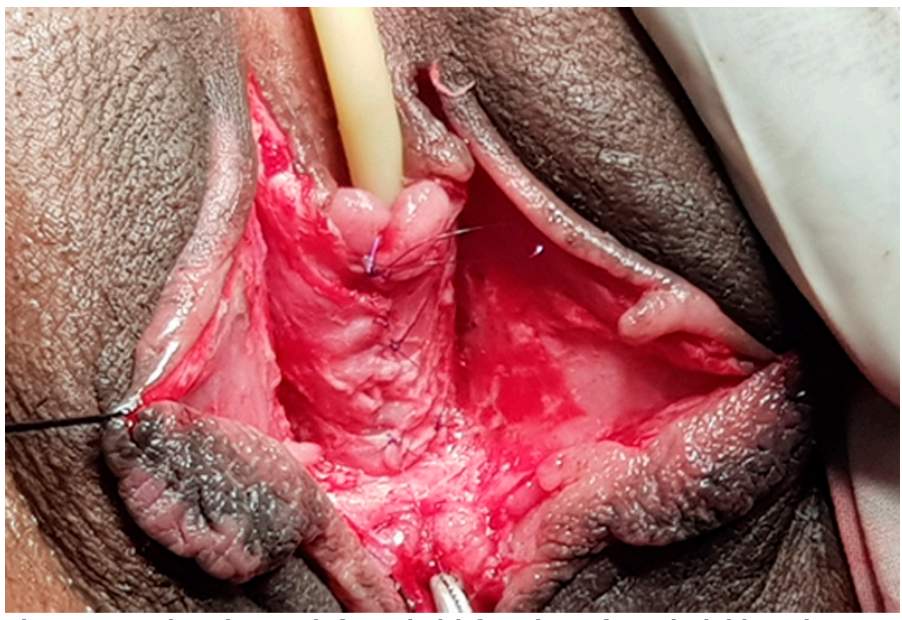

Figure 3: Urethroplasty reinforced with fatty layer from the labia majora.

\section{DISCUSSION}

Urologists rarely confront cases with abnormal urethral opening in adult female patients. These patients usually present with true urinary incontinence. ${ }^{3}$ Most of the cases reviewed in literature are of BEEC. It is extremely rare for epispadias to occur without bladder exstrophy, especially in females (3-4 times less common than in males). Mostly, it occurs sporadically. ${ }^{4}$ The present case, had epispadias with bifid clitoris, which presented to us with the chief complaint of urinary incontinence in a 23-year female.

Female epispadias has been classified into three degrees by Davis. ${ }^{5}$ Female with patulous urethra is termed as mild form; while in intermediate form, most of the urethra is split dorsally and in severe form, cleft involves the whole urethra extending up to the bladder neck. Our patient belonged to the category of intermediate form of Davis classification.
In such patient, if proper history and examination, especially of external genitalia, are not done, diagnosis concisely be missed. Patient can present with recurrent urinary tract infection (UTI). Females have social disturbances and sexual dysfunction. Incorrect diagnosis and mismanaged patients have led to anxiety and hopelessness in young women, so early diagnosis and treatment is very important reducing the psychosocial and psychosexual problems and preventing continuous urinary dribbling.

Micturating cystourethrogram (MCUG) is essential to rule out reflux and other causes of incontinence. Urodynamic studies reveal poor outlet resistance. Urethrao-cystoscopy is performed in all cases to assess bladder neck, bladder capacity and exact location of ureteral orifices. In epispadias, ureterovesical junction is deficient intrinsically with more lateral opening of both ureters, resulting in reflux. The reported incidence of reflux is $30 \%$ to $75 \% .{ }^{6}$ Our patient did nothave this abnormality on MCUG.

The objectives of prior reported cases were surgical repair to achieve urinary continence with reconstruction of functional and cosmetically acceptable genitalia and to prevent the involvement of upper urinary tract. The same was achieved in our case.

Isolated female epispadias without bladder extrophy is rare congenital syndrome among the urethral anomalies. Detailed history and careful and proper examination is very important for early diagnosis. Urinary continence and the reconstruction of functional and cosmetically acceptable genitalia are the cornerstones of surgery.

\section{ETHICAL APPROVAL:}

After approval from ERC and taking consent from patient this case was written and pictures of genitals taken and included in this case report.

\section{CONFLICT OF INTEREST:}

Authors declared no conflict of interest.

\section{AUTHORS' CONTRIBUTION:}

SAK: Manuscript writing. HM: Literature search.

SA: Final proof reading.

\section{REFERENCES}

1. Jonuzi A, Popovic N, Zvizdic Z, Milišic E, Karavdic K, Paddy D. Female epispadias presenting as urinary incontinence. APSP J Case Rep 2017; 8:10.

2. Tantibhedhyangkul J, Copland SD, Haqq AM, Price TM. A case of female epispadias. Fertil Steril 2008; 90:2017.

3. Shetty MK, Bhaskaran A, Sen TK. Female epispadias. Afr J Paediatr Surg 2011; 8:215-7.

4. Kajbafzadeh AM, Tajik P, Payabvash S, Farzan S, Solhpour AR. Bladder exstrophy and epispadias complex in sibling case report and review of literature. Pediatr Surg Int 2006; 22:767-70

5. Davis DM. Epispadias in females and its surgical treatment. Surg Gynaecol Obstet 1928; 47:680-9

6. Gearhart JP, Peppas DS, Jeffs RD. Complete genitourinary reconstruction in female epispadias. J Urol 1993; 149:1110-13. 